\title{
Selenium biomarkers in prostate cancer cell lines and influence of selenium on invasive potential of PC3 cells
}

\section{Wouter Hendrickx $^{1}{ }^{*}$, Julie Decock ${ }^{2}$, Francis Mulholland ${ }^{3}$, Yongping Bao ${ }^{1}$ and Susan Fairweather-Tait ${ }^{1}$}

1 Department of Nutrition, Norwich Medical School, University of East Anglia, Norwich, UK

2 School of Biological Sciences, University of East Anglia, Norwich, UK

${ }^{3}$ Institute of Food Research, Norwich Research Park, Norwich, UK

Edited by:

Paolo Pinton, University of Ferrara, Italy

\section{Reviewed by:}

Frederique Gaits-lacovoni, Institut

National de la Santé et de la

Recherche Médicale, France

Pier Giorgio Petronini, University of

Parma, Italy

\section{${ }^{*}$ Correspondence}

Wouter Hendrickx, Department of Nutrition, Norwich Medical School, University of East Anglia, Earlham

Road, Norwich NR4 7TJ, UK

e-mail:wouterhendrickx79@ gmail.com
Dietary selenium intake has been linked to reduced cancer risk, however the underlying mechanisms are yet unknown. We question the commonly used practice of applying selenium concentrations found in human blood to in vitro studies and evaluated the utility of biomarkers, e.g., glutathione peroxidase 1 (GPx1) and thioredoxin reductase 1 (TrxR1), to determine appropriate selenium levels for in vitro work. Furthermore, we investigated the effects of Se-methylselenocysteine (SeMSC) on prostate cancer cell migration and invasion. After excluding cytotoxicity, we demonstrated that prostate cancer cell lines respond differently to selenium treatment as observed through biomarker assessment. We found that the maximum levels of GPx1 activity and TrxR1 expression were reached at lower selenium concentrations in LNCaP compared to PC3 cells, and PC3 compared to DU145 cells. Therefore the use of selenium concentrations extrapolated from human studies for in vitro work may be applicable when further informed using a readout of selenium repletion including use of selenium responsive biomarkers. No effect on PC3 migration or invasion was observed after long term SeMSC treatment; however a slight increase was found when treatment was solely administered during the assay. The opposite could be observed when cells were cultured under low serum conditions, with a significant increase in migration upon long term but not upon acute SeMSC treatment. To conclude, these findings indicate that it is imperative to study the selenium sensitivity of an in vitro model preferably using biomarkers before investigating any effects on biological processes, or before comparing models.

Keywords: selenium, prostate cancer, invasion, biomarkers, GPx, TrxR1

\section{INTRODUCTION}

Selenium is an essential trace element and plays an important role in protection against cardiovascular disease, inflammation and inflammatory disorders, diabetes, infertility, and cancer (1). Selenium regulates protein function through its incorporation into selenoproteins as selenocysteine (1). Most selenoproteins have a functional role that impacts on chronic diseases such as cancer through the management of reactive oxygen species (ROS), present in numerous antioxidant defense systems throughout the body (2).

It has become clear that there is a very narrow margin between selenium deficiency and toxicity, with beneficial levels on health being dependent on the form of selenium, level of exposure, and selenium status (3). Selenium can be measured in whole blood, blood fractions (plasma, serum, red blood cells), hair, nails, and urine. Plasma selenium levels below $0.6 \mu \mathrm{M}(40-50 \mathrm{ng} / \mathrm{ml})$ are considered deficient, and risk of toxicity occurs at levels higher than $2 \mu \mathrm{M}(160 \mathrm{ng} / \mathrm{ml})$, with reports of toxic effects at concentrations higher than $3 \mu \mathrm{M}(250 \mathrm{ng} / \mathrm{ml})(4-6)$. Plasma selenium concentrations are considered to be adequate at 1.1-2 $\mu \mathrm{M}$ (90$160 \mathrm{ng} / \mathrm{ml}$ ), when selenoprotein P levels reach a plateau and cancer protective benefits may be maximized (7). Daily dietary recommendations have traditionally been based on the quantity of selenium required for optimal glutathione peroxidase 3 (GPx3) or erythrocyte GPx1 activity in blood. As such the dietary reference in the UK is set at $60 \mu \mathrm{g} / \mathrm{day}$ for women and $75 \mu \mathrm{g} /$ day for men although the mean intakes are $45-55 \mu \mathrm{g} / \mathrm{day}$ (1). In the US intakes are higher than in the UK, whereas in parts of China there are extremes of intake (related to local soil conditions), with both deficient and toxic levels (8).

The aim of the present work was to interrogate the value of extrapolating selenium concentrations found in human blood to in vitro studies. The use of biomarkers is now common practice in clinical nutrition studies and sometimes in animal models. However, in in vitro models, the amount of selenium used is at best extrapolated from "physiological relevant" serum concentrations. We evaluated the use of biomarkers such as glutathione peroxidase $1(\mathrm{GPx} 1)$ and thioredoxin reductase 1 (TrxR1) as markers for selenium repletion and this within the non-toxic range of selenium treatment. GPx1 is one of the most abundant selenoproteins and its expression is highly sensitive to a fall in selenium supply and oxidative stress $(9,10)$. In general, enhanced GPxl function is associated with increased protection against oxidative damage (11). TrxR1 is a highly selenium sensitive selenoprotein (11) and is of interest as a selenium biomarker for prostate cancer cells as it has been shown to respond to selenium treatment past the repletion point of GPx (12).

Further, we investigated the effect of selenium on cancer cell motility using migration and invasion assays of PC3 cells. Cancer 
cells often have enhanced growth and metastatic potential. To date, only a few studies have investigated the effect of selenium on migration and invasion of cancer cells in vitro (13-17). Although there are discrepancies between the findings from these studies, treatment with various selenium compounds has generally resulted in a decrease in the migration and, in some instances, the invasion of cancer cells. As no data have been published on the role of selenium in cell motility of prostate cancer cell lines, the aim of the present work was to determine the effect of Semethylselenocysteine (SeMSC) on the migration of PC3 cells and their invasion through matrigel.

There are limited comparative data on the toxicity of selenium compounds in cell systems, hence we compared the cytotoxicity of selenomethionine (SeMet), SeMSC, and selenite in three different prostate cancer cell lines (18-23). SeMet represents the major form of selenium in plant crops, while SeMSC can be found in broccoli, garlic, and onions, especially when grown under selenium-rich conditions $(24,25)$. Sodium selenite is water-soluble and is the most commonly used form in food and vitamin supplements (26).

In the present study the utility of GPxl and thioredoxin reductase 1 as in vitro selenium biomarkers was assessed in three different prostate cancer cell lines and the effects of selenium treatment on migration and invasion of PC3 cells was investigated.

\section{MATERIALS AND METHODS \\ CELL CULTURE}

LNCaP, PC3, and DU145 are cell lines derived from prostate cancer metastasis isolated from the lymph nodes, bone, and brain, respectively. All cell lines were procured from the American Type Culture Collection bank (ATCC) and were maintained in Dulbecco's Modified Eagle Medium/F12 (DMEM/F12) plus GlutaMAX ${ }^{\mathrm{TM}}(2.5 \mathrm{mM}$ L-Alanyl-L-Glutamine) with Hyclone-defined fetal bovine serum (FBS, Thermo Scientific) and 1\% penicillin-streptomycin (penicillin 5000 units $/ \mathrm{ml}$, streptomycin $5000 \mu \mathrm{g} / \mathrm{ml}$, Gibco). The use of Hyclone-defined FBS containing $380 \mathrm{nM}$ total selenium, according to manufacturer's batch analysis, resulted in control samples containing $38 \mathrm{nM}$ or $10 \mathrm{nM}$ total selenium under respectively $10 \%$ or low $2.5 \%$ serum conditions. Low $2.5 \%$ serum culture conditions were achieved by gradually reducing the amount of FBS. Selenium treatment of several cell lines with selenite (Sigma-Aldrich), SeMet (Sigma-Aldrich), or SeMSC (Sigma-Aldrich), was conducted for a duration $48 \mathrm{~h}$ for short-term (acute exposure) or for 30 days which allows longer term adaptation to occur.

\section{PROTEIN EXTRACTION AND OUANTIFICATION}

Cells were lysed at $80 \%$ confluency in $100 \mathrm{mM}$ Tris lysis buffer $\mathrm{pH}$ 7.4 supplemented with $0.1 \%$ Triton X-100 and a protease inhibitor cocktail (Roche). Cell pellets $\left(6 \times 10^{6}\right.$ cells) were ground in $350 \mu \mathrm{l}$ lysis buffer using a microcentrifuge tube pestle (Sample grinding kit, GE Healthcare) and sonicated on ice (Biologics 300V/T with $3.9 \mathrm{~mm}$ tip, $40 \%$ power, $50 \%$ pulse, $7 \mathrm{~min}$ ). After sonication, samples were centrifuged at $12,000 \times \mathrm{g}, 4^{\circ} \mathrm{C}$ for $10 \mathrm{~min}$, and stored at $-80^{\circ} \mathrm{C}$. The protein concentration was quantified using a BCA assay kit (Thermo Scientific) and absorbance was read at $562 \mathrm{~nm}$.

\section{MTT VIABILITY ASSAY}

Cells were seeded at $10 \times 10^{3}$ cells/well in a 96-well tissue culture plate. After $24 \mathrm{~h}$, the cells were treated with 10 different concentrations of selenium supplementation for $48 \mathrm{~h}$. The treatment was removed and cells were incubated with MTT $\left(0.45 \mathrm{mg} / \mathrm{ml}\right.$, Sigma) at $37^{\circ} \mathrm{C}$ for $2 \mathrm{~h}$. Finally cells were incubated with DMSO (Fisher) at room temperature for $5 \mathrm{~min}$. Changes in metabolism were used as an indicator of cell viability which was calculated from absorbance values at 550 and $630 \mathrm{~nm}$ (wavelength correction) using the MARS analysis software (BMG Labtech, version 1.11).

\section{GPX ENZYME ACTIVITY ASSAY}

Glutathione peroxidase activity was assessed using an assay mixture of $100 \mathrm{mM}$ Tris, $5 \mathrm{mM}$ EDTA, $1.5 \mathrm{mM}$ sodium azide, $0.1 \%$ Triton X-100, $0.25 \mathrm{mM}$ NADPH (Sigma), 3 mM glutathione (Sigma), and 1 unit glutathione reductase (Sigma). Cell extracts were used at $0.5-2 \mathrm{mg} / \mathrm{ml}$ according to the enzyme activity of each cell line. The rate of increase in absorbance at $340 \mathrm{~nm}$ was monitored at $37^{\circ} \mathrm{C}$ every $10 \mathrm{~s}$ for $15 \mathrm{~min}$ after the addition of $2.5 \mathrm{mM} t$-butyl hydroperoxide (Sigma). One unit GPx activity was defined as the oxidation of $1 \mu \mathrm{mol}$ of NADPH per minute and was related to the protein content of the cell lysate. Using the slope as determined by the MARS software (BMG Labtech V1.11), GPx activity was calculated using the following equation with $0.00379 \mu \mathrm{M}^{-1}$ as the NADPH extinction coefficient, slope as Delta A 340/min, and units GPx in micromoles NADPH/min:

$$
\left(\frac{\text { Well volume }}{\text { Sample volume }}\right) \times\left(\frac{\text { Slope }}{0.00379 \mu \mathrm{M}^{-1}}\right)=\frac{\text { Units GPx }}{g \text { protein extract }}
$$

\section{TrXR1 WESTERN BLOT}

Cell lysates were resuspended in $4 \times$ NuPAGE$^{\circledR}$ LDS sample buffer (Invitrogen) and resolved on a NuPAGE ${ }^{\circledR}$ Novex 4-12\% Bis-Tris mini gel (Invitrogen) at $200 \mathrm{~V}$ before transfer at $30 \mathrm{~V}$ onto a PVDF membrane (Immobilon-FL, Millipore). The membranes were blocked for $1 \mathrm{~h}$ in protein-free T-20 TBS blocking buffer (Thermo) at room temperature. The membranes were probed overnight at $4^{\circ} \mathrm{C}$ with rabbit anti-TrxR1 antibody at 1:1000 (Santa Cruz) and chicken anti-GAPDH at 1:20,000 (Millipore). The secondary donkey anti-rabbit (Li-Cor) and donkey anti-chicken ( $\mathrm{Li}$ Cor) infrared labeled antibodies diluted at 1:10,000 and 1:20,000 in $50 \%$ blocking buffer $/ 10 \mathrm{mM}$ PBST/0.1\% SDS were used for $2 \mathrm{~h}$ at room temperature. Bound antibodies were visualized and quantified using the Odyssey imaging system (Li-Cor).

\section{MIGRATION AND INVASION ASSAYS}

Prior to the assays, 10\% serum cultured PC3 cells were labeled with $10 \mathrm{mg} / \mathrm{ml}$ DilC12 stain (BD Biosciences) in phenol-red free DMEM/F12 GlutaMAX ${ }^{\mathrm{TM}}$ (Invitrogen) media for $1 \mathrm{~h}$ at $37^{\circ} \mathrm{C}$. In addition, the assays were also performed using cells which were adapted to low $2.5 \%$ serum levels for 30 days. After labeling, the cells were resuspended in serum free, phenol-red free media, and loaded on top of an $8 \mu \mathrm{m}$ BD Matrigel ${ }^{\mathrm{TM}}$ Matrix-coated membrane of a BD BioCoat ${ }^{\mathrm{TM}}$ Tumor Invasion System (BD Biosciences). Uncoated BD Falcon $^{\mathrm{TM}}$ FluoroBlok ${ }^{\mathrm{TM}}$ 24-multiwell insert plates were included as migration controls. Media containing 5\% serum was added to the bottom chamber to create a chemoattractant gradient between the top and bottom chamber. The Fluoroblok plates were covered with sterile gas permeable membrane (Axygen) 
and incubated in a $5 \% \mathrm{CO}_{2}$ and $37^{\circ} \mathrm{C}$ controlled plate reader for 22-44 h. The number of cells migrating or invading was measured every $5 \mathrm{~min}(544,590 \mathrm{~nm})$ and fluorescence units were collected at endpoint and analyzed using the MARS software (BMG Labtech, version 1.11).

\section{STATISTICAL ANALYSIS}

Statistical significance was determined using a two-tailed $t$-test, and significance level was set at $p \leq 0.05$ or 0.005 . Standard deviations were shown as error bars. Curve fitting was performed where possible using Graphpad Prism 5.

\section{RESULTS}

\section{EFFECT OF SELENIUM TREATMENT ON CELL VIABILITY IN VITRO}

Epidemiological data have demonstrated a narrow margin between selenium deficiency and toxicity. It is therefore important to determine the range of selenium concentrations which correspond to non-toxic, optimal levels in vitro systems when investigating the effects of selenium on biological processes. In order to demonstrate minimal toxicity of the selenium compounds and concentrations used, MTT viability analyses of SeMSC $(0.5-200 \mu \mathrm{M})$, SeMet $(0.5-200 \mu \mathrm{M})$, and sodium selenite $(0.5-$ $50 \mu \mathrm{M})$ were performed. The LC50/48 h of SeMSC was recorded and compared to those of SeMet and sodium selenite (Table 1; Figure 1).

After treatment with SeMSC we observed a LC50/48 h value of $400-800 \mu \mathrm{M}$ in PC3, $200 \mu \mathrm{M}$ in LNCaP, and $150 \mu \mathrm{M}$ in DU145 cells. Overall, in comparison to the commonly used selenium compounds, SeMSC was found to be 5-10 times less toxic than the sodium selenite but 2 times more toxic than the SeMet. Among the three cell lines studied, PC3 cells were considerably less sensitive to selenium toxicity. These findings are in line with the published literature on selenium toxicity in prostate cancer in vitro when

Table 1 | LC50/48 $\mathrm{h}$ concentrations of SeMSC, SeMet, and sodium selenite.

\begin{tabular}{lccc}
\hline & SeMet $(\mu \mathbf{M})$ & SeMSC $(\mu \mathbf{M})$ & Sodium selenite $(\mu \mathbf{M})$ \\
\hline PC3 & $>800^{*}$ & $606.3^{\dagger}$ & $7.9^{\dagger}$ \\
LNCaP & $400^{*}$ & $175.6^{\dagger}$ & $4.5^{\dagger}$ \\
DU145 & $300^{*}$ & $141.7^{\dagger}$ & $3.5^{\dagger}$
\end{tabular}

The LC50 values for the various prostate cancer cell lines were determined at $48 \mathrm{~h}$ using the MTT viability assay. ${ }^{+}$Calculated using Graphpad Prism 5 curve fitting. *Estimate from lower concentrations. LC, lethal concentration.

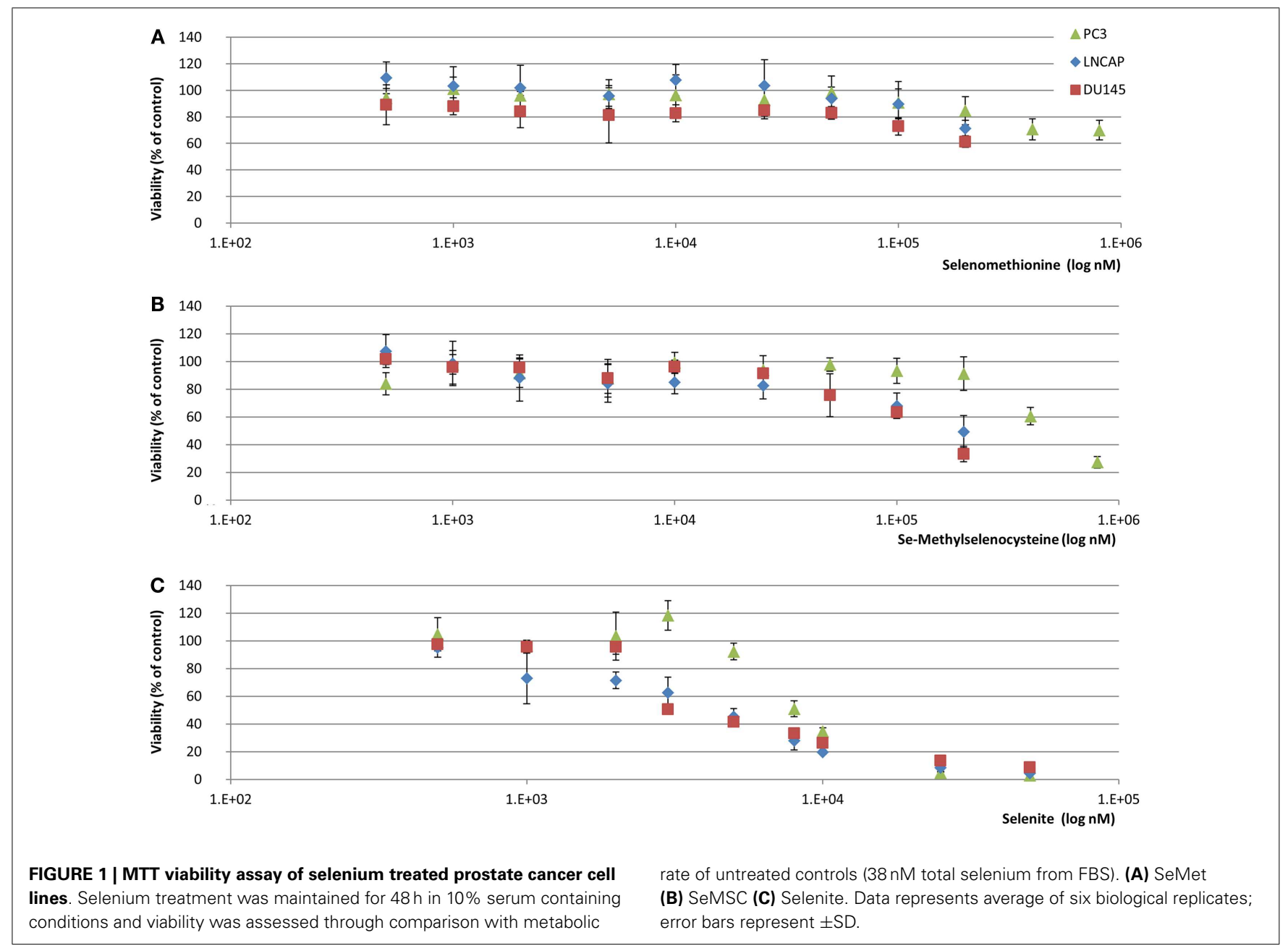


considering the different methodologies, compounds, cell lines, and treatment duration used (18-21).

Using identical culture and treatment conditions for all three cell lines, we found that DU145 cells were more sensitive to selenium toxicity than $\mathrm{LNCaP}$ and PC3 cells. These data indicate that the concentrations used in the biomarker activity and invasion assays are in the non-toxic range and hence do not adversely affect or interfere with the respective results.

\section{EFFECT OF SELENIUM TREATMENT ON SELENIUM BIOMARKERS IN VITRO}

Glutathione peroxidase 1 activity is often used as a biomarker of selenium status and reaches a plateau at plasma selenium concentrations of $1.3 \mu \mathrm{M}(80-120 \mathrm{ng} / \mathrm{ml})$ (27). In cell culture, GPx1 activity is reported to plateau at 30-50 nM selenite and 250-2000 nM SeMet (28). However, various in vivo studies have suggested that GPx activity is not a sensitive or reliable biomarker at moderate to high selenium intakes. A rise in serum selenium concentration (from 123 to $196 \mathrm{ng} / \mathrm{ml}$ ) has been associated with an increase in prostate tissue selenium concentration (1.4-1.6 $\mu \mathrm{g} / \mathrm{g})$ although no effect on GPx activity was observed in prostate tissue (5). These discongruent patterns might have been caused by a high baseline selenium concentration in the study population. Another study published findings that showed a positive correlation between GPx activity in prostate tumor tissue and Gleason score, while an inverse correlation was observed with Selenium binding protein 1 (29). TrxR1 has been associated with increasingly aggressive tumors (30) and has even shown potential as an anti-cancer target (31). As part of a New Zealand prostate cancer selenium trial, the relationship between serum selenium concentration and both TrxR and GPx activity in erythrocytes of 43 participants, aged 50-75 years, with PSA levels above $4 \mathrm{ng} / \mathrm{ml}$, and a negative biopsy was investigated (12). This study reported a positive correlation between baseline serum selenium concentrations (59-128 ng/ml) and both enzyme activities. However, after supplementation (200 or $400 \mu \mathrm{g} /$ day from selenium-enriched yeast) a $66 \%$ increase in serum selenium concentration was reflected in an $80 \%$ increase in TrxR activity but not by an increase in GPx activity. This finding suggests that TrxR activity might be a good biomarker at high selenium levels. Hence, we investigated GPx activity and TrxR1 protein expression as selenium biomarkers in LNCaP, PC3, and DU145 cells in response to $48 \mathrm{~h}$ or 30 day treatment with SeMSC and SeMet.

\section{Effect of SeMSC and SeMet dose-response adaptation on GPX activity under $10 \%$ serum culture conditions}

As different selenium compounds and culture conditions variably affect the selenium status of the cell lines it is important to note that the blood selenium status and biomarker plateau may not necessarily translate to the appropriate in vitro concentration of selenium (32). We measured the GPx activity in LNCaP, PC3, and DU145 cells following 30 day long term exposure and adaptation to SeMSC (500 and $2000 \mathrm{nM}$ ) and SeMet $(500 \mathrm{nM})$ to determine the maximum GPx activity and the selenium dose at which this occurs.

Significantly different responses in GPx activity were observed between the three cell lines after exposure to different selenium concentrations (Figure 2A). In LNCaP cells, neither SeMSC nor SeMet induced a significant increase in GPx activity. GPx activity levels were elevated, although not significant, to a maximum of $19.6 \pm 1.9 \mathrm{U} / \mathrm{g}$ after treatment with $500 \mathrm{nM}$ SeMSC compared to control treatment $(17.4 \pm 0.4 \mathrm{U} / \mathrm{g})$, whereas SeMet did not affect activity levels. These findings might indicate that LNCaP cells are replete at the selenium concentration $(38 \mathrm{nM}$ total selenium) used in the control treatment. In PC3 cells, a significant 1.4 -fold increase in GPx activity $(p=0.003)$ was found between the control condition $(5.1 \pm 0.3 \mathrm{U} / \mathrm{g})$ and $500 \mathrm{nM} \mathrm{SeMSC}$ treatment $(6.9 \pm 0.4 \mathrm{U} / \mathrm{g})$, with a further, although not statistically significant, increase after treatment with $2000 \mathrm{nM}$ SeMSC $(7.4 \pm 0.9 \mathrm{U} / \mathrm{g})$. Using $500 \mathrm{nM}$ SeMet a significant increase in GPx activity $(11.7 \pm 1.6 \mathrm{U} / \mathrm{g})$ was observed compared to the control $(5.1 \pm 0.3 \mathrm{U} / \mathrm{g}, p=0.002)$. In DU145 cells, high concentrations of SeMSC, up to $2000 \mathrm{nM}$, were required to induce a 3.9-fold increase in GPx activity $(1.3 \pm 0.1 \mathrm{U} / \mathrm{g}, p<0.001)$. Even higher SeMSC concentrations may be required to obtain maximum GPx activity as there was a large difference in activity levels between treatment with 500 and $2000 \mathrm{nM}$ SeMSC. Treatment with $500 \mathrm{nM}$ SeMet increased GPx activity to $1.6 \pm 0.1 \mathrm{U} / \mathrm{g}$.

Comparison of GPx activity levels between SeMet and SeMSC treatments revealed significant 1.7- and 5.3-fold higher levels at $500 \mathrm{nM}$ SeMet compared to $500 \mathrm{nM}$ SeMSC for PC3 and DU145 cells respectively. The GPx activity at $500 \mathrm{nM}$ SeMet was even higher than that at $2000 \mathrm{nM}$ SeMSC for both cell lines, suggesting that SeMet might have a more profound effect on GPx activity in these cells. A previous study comparing the Gpx inducing potential of selenium compounds has demonstrated a GPxl plateau in $\mathrm{LNCaP}$ cells at $30 \mathrm{nM}$ selenite, at $50 \mathrm{nM}$ selenate, and at $250 \mathrm{nM}$ SeMet (28). In PC3 cells a plateau occurred at $40 \mathrm{nM}$ selenite, at $500 \mathrm{nM}$ selenate, and at $2000 \mathrm{nM}$ SeMet. The authors also observed that GPx1 RNA expression was modulated to a similar extent. Discrepancies between their findings and our data might partly be due to differences in assessment methods (activity assay versus western blot densitometry) and culture conditions, including the culture media and selenium content of the control media. Nevertheless, in accordance to our SeMSC findings they report a higher SeMet induced maximum GPx value in LNCaP cells compared to PC3 cells.

The baseline GPx activity was significantly different between the three cell lines, even when grown under identical conditions. Compared to PC3 and DU145 cells, 3-fold and 40-fold higher GPx activity levels were found in LNCaP cells. The activities under control conditions were 89,70 , and $31 \%$ of the maximum GPx activity of SeMSC-treated LNCaP, PC3, and DU145 cells, respectively (Figure 2A), supporting the hypothesis by Rebsch and Colleagues that GPx activity might not be the optimal selenium biomarker for comparison of prostate cancer cell lines at higher selenium concentrations (28). The GPx1 activity values observed in PC3 and DU145 control conditions were similar to those published by Jung et al. who compared the levels of different antioxidant enzymes in LNCaP, PC3, and DU145 cells (33). However, they found LNCaP GPx activity values of about half of those observed in our study which might be explained by differences in cell culture conditions such as the media formulation or the confluency of cells at time of harvesting. 

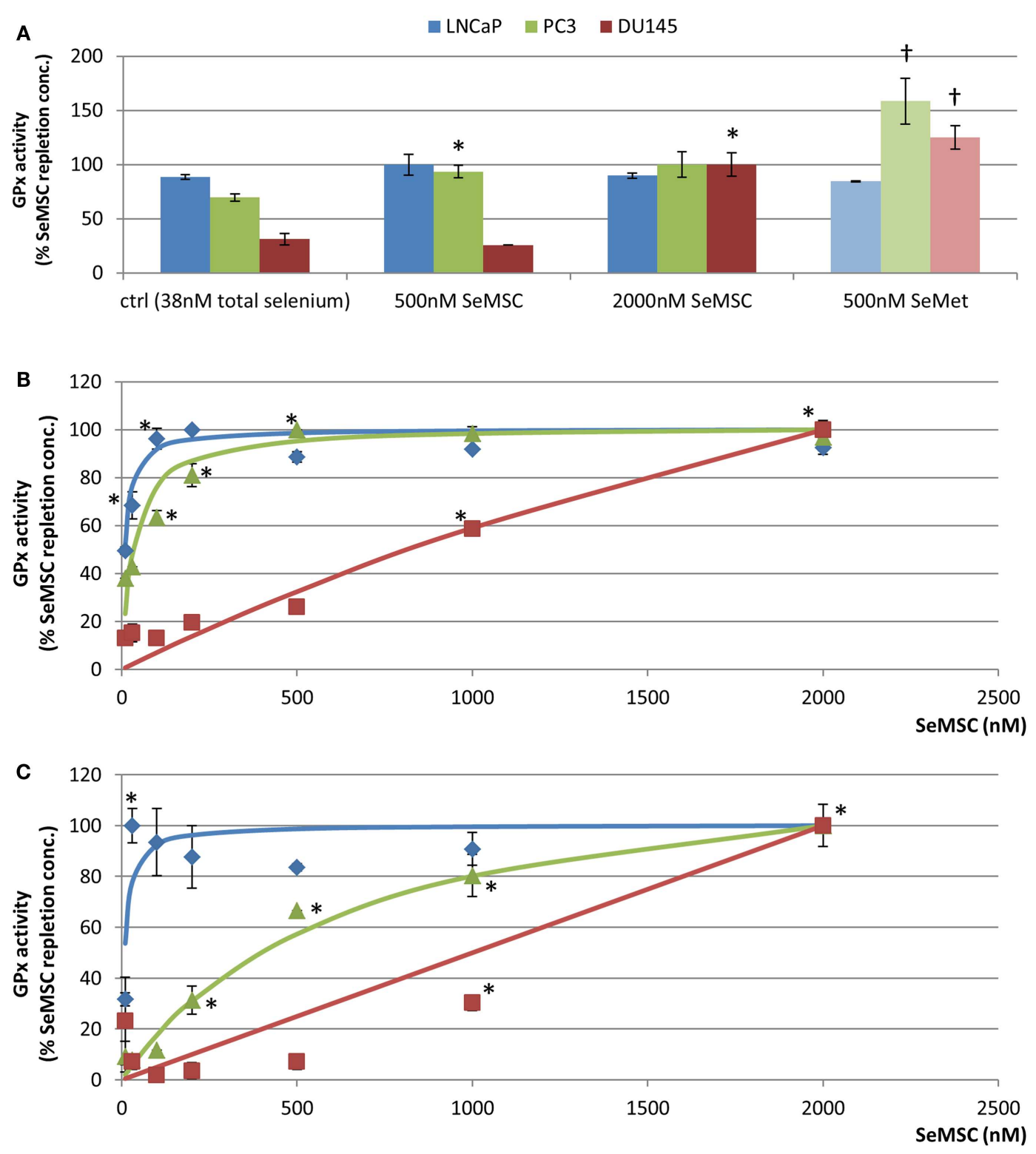

FIGURE 2 | GPx1 activity in prostate cancer cell lines. GPx activity was expressed as a percentage compared to the activity at GPx plateau for cells maintained in (A) $10 \%$ serum after 30 day selenium adaptation to SeMSC or SeMet (B) $2.5 \%$ serum after $48 \mathrm{~h}$ of SeMSC treatment (C) $2.5 \%$ serum after 30 day selenium adaptation to SeMSC. Data represent average of three biological and three technical replicates, error bars $\pm S D$. * Significant increase compared to previous concentration of SeMSC, ${ }^{\dagger}$ significant increase compared to equal SeMSC concentration $p<0.05$. Lines represent curve fit using Michaelis-Menten formula [Graphpad Prism 5, $y=\left(V_{\max } \times X\right) /\left(K_{\mathrm{m}}+X\right)$ ] with (B) $\mathrm{LNCaP}, V_{\max }=7.38$, $K_{\mathrm{m}}=9.37$, and PC3, $V_{\max }=2.27, K_{\mathrm{m}}=33.77$, and (C) LNCaP, $V_{\max }=24.43$, $K_{\mathrm{m}}=8.71$, and PC3, $V_{\max }=4.68, K_{\mathrm{m}}=658.8$.

\section{Effect of acute and long term adaptation to SeMSC dose on GPX activity under low serum culture conditions}

The effect of culture conditions on GPx activity was further explored in cells adapted to low serum conditions (2.5\% serum) containing low baseline selenium levels ( $10 \mathrm{nM}$ total selenium). The impact of both long- (30 days) and short-term (48 h) exposure to SeMSC was investigated to determine GPx activity steady state levels (Figures 2B,C).

Differences were found in the maximum GPx activity levels as well as in the concentration of selenium at which this GPx plateau occurred. LNCaP cells showed the highest GPx activity $(7.7 \pm 0.02 \mathrm{U} / \mathrm{g})$ with a 2 -fold increase compared to the control condition $(3.8 \pm 0.1 \mathrm{U} / \mathrm{g}, p<0.001)$, and reached GPx repletion at a lower SeMSC supplementation concentration (100 nM) compared to the other cell lines. In PC3 cells, the repletion point for GPx activity $(2.3 \pm 0.0 \mathrm{U} / \mathrm{g})$ was reached at $500 \mathrm{nM}$ SeMSC. The GPx activity of the DU145 control condition was 4.5- and 19-fold lower than those of PC3 and LNCaP cells. The GPx activity significantly $(p<0.001)$ increased between $500 \mathrm{nM}(0.4 \pm 0.0 \mathrm{U} / \mathrm{g})$, $1000 \mathrm{nM}(1.0 \pm 0.0 \mathrm{U} / \mathrm{g})$, and $2000 \mathrm{nM}$ SeMSC $(1.7 \pm 0.1 \mathrm{U} / \mathrm{g})$. 
Comparing the three cell lines, the GPx activity of the respective control conditions were $87 \%$ lower than the maximum activity for DU145, 62\% for PC3, and 50\% for LNCaP cells. The maximum GPx activities correspond with the $V_{\max }$ of the Michaelis-Menten curve fit whenever it was possible to calculate these (LNCaP $7.37 \pm 0.15 \mathrm{U} / \mathrm{g}$, PC3 $2.27 \pm 0.08 \mathrm{U} / \mathrm{g}$ ).

Long term adaptation of cells under low serum conditions resulted in even greater changes in GPx activity in $\mathrm{LNCaP}$ cells (Figure 2C). A GPx plateau was reached at $30 \mathrm{nM}$ SeMSC with a $>3$-fold higher GPx activity $(25.7 \pm 1.7 \mathrm{U} / \mathrm{g})$ compared to the maximum GPx activity $(7.7 \pm 0.02 \mathrm{U} / \mathrm{g})$ observed under short-term treatment. Conversely, the maximum GPx activity $(1.5 \mathrm{U} \pm 0.05 / \mathrm{g})$ in DU145 cells was found to be lower than the maximum activity under short-term treatment $(1.7 \pm 0.1 \mathrm{U} / \mathrm{g})$. In PC3 cells, maximum GPx activity $(3.5 \pm 0.3 \mathrm{U} / \mathrm{g})$ was obtained at $2000 \mathrm{nM}$ SeMSC which was not statistically different from the activity at $1000 \mathrm{nM}$ SeMSC $(2.8 \pm 0.3 \mathrm{U} / \mathrm{g})$. Comparing the three cell lines again, the GPx activity of the control conditions were $68-91 \%$ lower than their respective repletion point. The maximum observed GPx activities correspond with the $V_{\max }$ of the Michaelis-Menten curve fit whenever it was possible to calculate these (LNCaP $24.4 \pm 0.1 .9 \mathrm{U} / \mathrm{g}, \mathrm{PC} 34.7 \pm 0.4 \mathrm{U} / \mathrm{g}$ ). Longer term adaptation for 30 days to SeMSC treatment under low serum conditions caused lower SeMSC concentration to yield maximum GPx activity in LNCaP cells while higher concentrations were required in PC3 and DU145 cells (Table 2). When comparing 10 and $2.5 \%$ serum conditions, it is apparent that the selenium content of serum can obscure an increase in GPx activity after long term selenium treatment. In particular, LNCaP cells show no increase in GPx activity under 10\% serum containing conditions while only a small increase could be observed for PC3 cells compared to a pronounced increase in GPx activity under low serum conditions.

\section{Effect of acute SeMSC treatment on TrxR1 expression under low serum culture conditions}

To the best of our knowledge, only one study to date has investigated the effect of selenium treatment on TrxR activity in prostate cancer cell lines. In this work no change in TrxR activity was reported using physiologically relevant doses of selenium in LNCaP and PC3 cells (19). High selenite doses ( $>5 \mu \mathrm{M})$ resulted in a decrease in TrxR activity. However, in the normal prostate $\mathrm{BPH}-1$ cell line an increase in TrxR activity was observed using selenite treatment compared to control. TrxR1 has recently been shown to respond to both selenium and Iberin treatment (34). In accordance, we found that treatment of Caco- 2 cells with 25 and $200 \mathrm{nM}$ SeMSC resulted in a 1.4- and 1.5-fold increase of TrxR1 expression respectively, while combination treatment of $200 \mathrm{nM}$ SeMSC with $6 \mu \mathrm{M}$ Iberin resulted in a 2.1 -fold increase (data not shown). Western blotting revealed that a high molecular weight form of TrxR1 was more selenium and Iberin responsive after $48 \mathrm{~h}$ treatment than the $55 \mathrm{kDa}$ lower molecular weight form. However, the identity and function of this high molecular weight form remains unknown.

We studied the TrxR1 response in DU145, LNCaP, and PC3 cells exposed to SeMSC treatment under low serum conditions (Figure 3). Under 2.5\% serum culture conditions, short-term
Table 2 | SeMSC concentrations at which GPx activity plateaus.

\begin{tabular}{llllll}
\hline Time & Serum (\%) & $\begin{array}{l}\text { SeMSC (nM) } \\
\text { at GPx } \\
\text { plateau }\end{array}$ & $\begin{array}{l}\text { Max GPx } \\
\text { activity } \\
\text { (U/g) }\end{array}$ & $\boldsymbol{V}_{\text {max }}(\mathbf{U} / \mathbf{g})$ \\
\hline LNCaP & 30 days & 10 & ctrl (38) & 19.6 & n.a. \\
& $48 \mathrm{~h}$ & 2.5 & 100 & 7.4 & $7.37 \pm 0.15$ \\
& 30 days & 2.5 & 30 & 25.7 & $24.4 \pm 0.1 .9$ \\
PC3 & 30 days & 10 & 500 & 7.4 & n.a. \\
& 48 $h$ & 2.5 & 500 & 2.3 & $2.27 \pm 0.08$ \\
& 30 days & 2.5 & 1000 & 2.8 & $4.7 \pm 0.4$ \\
DU145 & 30 days & 10 & $\geq 2000$ & 1.3 & n.a. \\
& 48h & 2.5 & $\geq 2000$ & 1.7 & n.a. \\
& 30 days & 2.5 & $\geq 2000$ & 1.5 & n.a.
\end{tabular}

Maximum observed GPx activity of LNCaP, PC3, and DU145 cells was assessed using a GPx activity assay and $V_{\max }$ was calculated using Michaelis-Menten curve fitting in Graphpad Prism 5.

n.a., not available; GPx, glutathione peroxidase.

treatment for $24 \mathrm{~h}$ of DU145 cells with $100 \mathrm{nM}$ SeMSC induced a 2.1-fold increase in expression, reaching a plateau for the low molecular weight form of TrxR1. Looking at the high molecular weight form, a maximum fold increase of 2.9 was obtained after $24 \mathrm{~h}$ treatment with $2000 \mathrm{nM}$ SeMSC, however this cannot be established with certainty as being the plateau point. The high molecular weight TrxR1 was found to be more strongly expressed than the low molecular weight form in both normal and low serum cultured DU145 cells. Low serum culture conditions revealed a maximum expression of the high molecular weight TrxR1 form in LNCaP cells after treatment with $200 \mathrm{nM}$ SeMSC. Surprisingly, this 2.5-fold increase in expression is reduced to 1.4-fold at SeMSC concentrations higher than $200 \mathrm{nM}$. In contrast with the data obtained from the DU145 cells but in accordance with those from the Caco-2 cells, the lower molecular weight form shows a stronger expression than the higher molecular weight form. In low serum cultured PC3 cells, repletion of TrxR1 expression can be seen for both the high and low molecular weight form after $24 \mathrm{~h}$ treatment with $500 \mathrm{nM}$ SeMSC with a 1.6- and 1.1-fold increase respectively. Similar to the LNCaP cells, TrxR1 expression decreased at SeMSC concentrations higher than those of the plateau point. In accordance with the DU145 cells, but not LNCaP and Caco-2 cells, the high molecular weight TrxR1 form shows overall a stronger expression than the low molecular weight form.

When comparing the SeMSC levels required for TrxR1 repletion, we found that the various prostate cancer cell lines respond differently (Table 3 ). Lower concentrations of selenium were needed for LNCaP cells than for PC3 cells and for PC3 cells than for DU145 cells, which is in agreement with the results of the GPx activity assays. These findings are also in agreement with previously published data on TrxR activity in these cell lines. For instance, PC3 cells have been shown to have a more efficient antioxidant system including a higher TrxR activity than LNCaP cells, while DU145 cells have a slightly higher TrxR activity than PC3 cells $(31,35)$. It might be of interest to study the TrxR1 selenium responsiveness in long term low serum conditions in more 



FIGURE 3 | TrxR1 expression in prostate cancer cell lines. Cell lines were cultured in either low serum $(2.5 \%)$ media containing $10 \mathrm{nM}$ of total selenium (control) or media supplemented with 30-2000 nM SeMSC for $48 \mathrm{~h}$. (A) Representative image of western blot showing TrxR1 protein bands in green and loading control GAPDH in red. (B-D) Quantification of TrxR1 expression normalized to GAPDH and expressed as percentage of control with (B) LNCaP, (C) PC3, (D) DU145, no technical or biological replicates. detail. Hereby a TrxR1 activity assay might be a better approach for this purpose since measurement of biomarker activity is functionally more relevant compared to biomarker expression and western blotting is a less accurate method for quantification. Furthermore, it is imperative that the nature and relation of the two TrxR1 forms are explored in future studies. 
Table 3 | SeMSC concentrations at which TrxR1 expression plateaus as determined by western blotting.

\begin{tabular}{llll}
\hline & Time (h) & Serum (\%) & $\begin{array}{l}\text { SeMSC (nM) at TrxR1 HMW } \\
\text { band repletion }\end{array}$ \\
\hline LNCaP & 48 & 2.5 & 200 \\
PC3 & 48 & 2.5 & 500 \\
DU145 & 48 & 2.5 & $\geq 2000$ \\
\hline
\end{tabular}

HMW, higher molecular weight.

\section{EFFECT OF SEMSC TREATMENT ON THE MIGRATION AND INVASION OF PC3 CELLS}

The effect of selenium treatment on the migratory and invasive ability of prostate cancer cell lines has not been reported yet. Furthermore, although SeMSC is a dietary relevant form of selenium, no data on its effect on migration or invasion of cancer cells are available. Therefore, we investigated the response of acute or long term SeMSC treatment on both the migratory and invasive behavior of PC3 cells (Figure 4).

We found that long term treatment with SeMSC showed no effect on PC3 migration or invasion through Matrigel, whereas acute treatment for the duration of the assay $(22 \mathrm{~h})$ resulted in an increase in migration and invasion. A dose-response study showed a 1.4-fold increase in migration across a range of 200$5000 \mathrm{nM}$ SeMSC $(130.4 \pm 16.1 \mathrm{FU} / \mathrm{h}, p=0.002)$ as compared to the control $(93.0 \pm 18.6 \mathrm{FU} / \mathrm{h})$ (Figure 4A). On the other hand a clear dose-response increase in invasion was observed (Figure 4B) with $500 \mathrm{nM}$ SeMSC $(64.4 \pm 13.7 \mathrm{FU} / \mathrm{h})$ and $2000 \mathrm{nM} \mathrm{SeMSC}$ $(70.9 \pm 8.0 \mathrm{FU} / \mathrm{h})$ compared to control cells $(56.1 \pm 4.4 \mathrm{FU} / \mathrm{h})$.

In addition, both the migration and invasion assays were repeated using low $2.5 \%$ serum cultured cells in order to achieve lower baseline selenium concentrations and a greater chemoattractant gradient. In contrast to the results obtained from $10 \%$ serum cultured cells, long term treatment under $2.5 \%$ serum containing conditions resulted in an increase in migration whereas no difference was found with acute treatment (Figure 4C). More specifically, a significant 1.9 -fold increase in migration $(2085.1 \pm 188.1 \mathrm{FU} / \mathrm{h}, p=0.0017)$ was observed with $2000 \mathrm{nM}$ SeMSC long term treatment compared to the control condition $(1078.8 .1 \pm 136.9 \mathrm{FU} / \mathrm{h})$ or $2000 \mathrm{nM}$ acute treatment $(1107.9 \pm 117.6 \mathrm{FU} / \mathrm{h})$. When investigating invasion, no difference was found for acute treatment whereas long term $2000 \mathrm{nM}$ SeMSC treatment resulted in a 1.8 -fold increase as compared to control treatment (data not shown). Therefore, we further investigated the effect of long term SeMSC treatment on PC3 invasion under low serum conditions using a dose-response invasion assay (Figure 4D). A 2.7- and 5-fold increase was found after treatment with $500 \mathrm{nM}(239.1 \pm 24.3 \mathrm{FU} / \mathrm{h}, p=0.003)$ or $1000 \mathrm{nM}$ $(440.3 \pm 99.9 \mathrm{FU} / \mathrm{h}, p=0.007)$ SeMSC respectively. Surprisingly, $2000 \mathrm{nM}$ SeMSC did not further increase invasion but instead reduced invasion back to a 2.4 -fold increase $(209.0 \pm 27.8 \mathrm{FU} / \mathrm{h}$, $p=0.006)$ compared to the control $(88.0 \pm 12.9 \mathrm{FU} / \mathrm{h})$.

Our data demonstrate an increased migration and invasion of PC3 cells after selenium treatment which are in agreement with publications linking selenoproteins to the invasive potential of macrophages (36). However, several reports have been published showing that selenium has an inhibitory effect on the migration and invasion of cancer cell lines using different forms and doses of selenium. For instance, small amounts of the selenium metabolite methylselenol $(<1 \mu \mathrm{M})$ have been shown to decrease both HT1080 migration and invasion by 53 and $76 \%$, respectively which might be partly attributed to a decrease in expression of the active form of MMP2. In contrast, no difference in invasion or migration was found after treatment with $5 \mu \mathrm{M}$ SeMet (14). On the other hand, selenite treatment has been reported to inhibit the invasion of HT1080 sarcoma cells but not their migration or adhesion (13). Further, selenite treatment has been shown to reduce expression of various MMPs in HT1080 sarcoma cells and biopsy derived glioma cells, while no effect on MMP expression was observed in HT1080 cells after selenate treatment. In another study, B16F10 murine melanoma cells treated with selenite showed a decreased migration in a wound healing assay and transwell migration assay. The authors suggest the reduction in migration might be caused by a decreased HIF- 1 and VEGF expression, regulated through a decreased IL-18 expression (17).

\section{DISCUSSION}

The present work questions the commonly used practice of using selenium concentrations found in human blood for in vitro studies and evaluated the utility of biomarkers such as GPxl activity and TrxR1 protein expression to determine appropriate selenium levels for in vitro work. We studied the use of GPx1 and TrxR1 as biomarkers of SeMSC treatment under different culture conditions and found that GPx activity and TrxR1 protein expression showed a similar selenium repletion pattern and that the effects of selenium treatment on both biomarkers were more pronounced under low $2.5 \%$ serum containing conditions. However, we noticed that the maximum levels of GPx1 activity and TrxR1 expression were reached at lower selenium concentrations in LNCaP cells compared to PC3 cells, and in PC3 cells compared to DU145 cells. As such we have been able to demonstrate that one particular physiological relevant dose of selenium, extrapolated from concentrations observed in human blood, can elicit different responses in different prostate cancer cell lines. Therefore using a read-out of selenium repletion such as selenium responsive biomarkers may assist with the selection of which selenium concentration to use in in vitro work. Further, we found no relation between the maximum biomarker level and the selenium concentration required to reach that biomarker repletion. For example, $\mathrm{LNCaP}$ cells reach the maximum GPx1 activity level at lower selenium concentrations than the other cell lines but their maximum GPx1 activity levels are higher than those of PC 3 or DU145 cells. Similarly, maximum protein expression of the high molecular weight TrxR1 form was lower in LNCaP cells compared to PC3 cells, and lower in PC3 cells compared to DU145 cells while lower selenium concentrations were required to result in TrxR1 repletion in LNCaP cells compared to PC3 and DU145 cells.

The effect of SeMSC on the migratory and invasive behavior of PC3 cells was examined under both normal and low serum culture conditions. Selenium treatment induced an increase in migration and invasion in long term low serum conditions. Further studies are required to determine whether the increased 

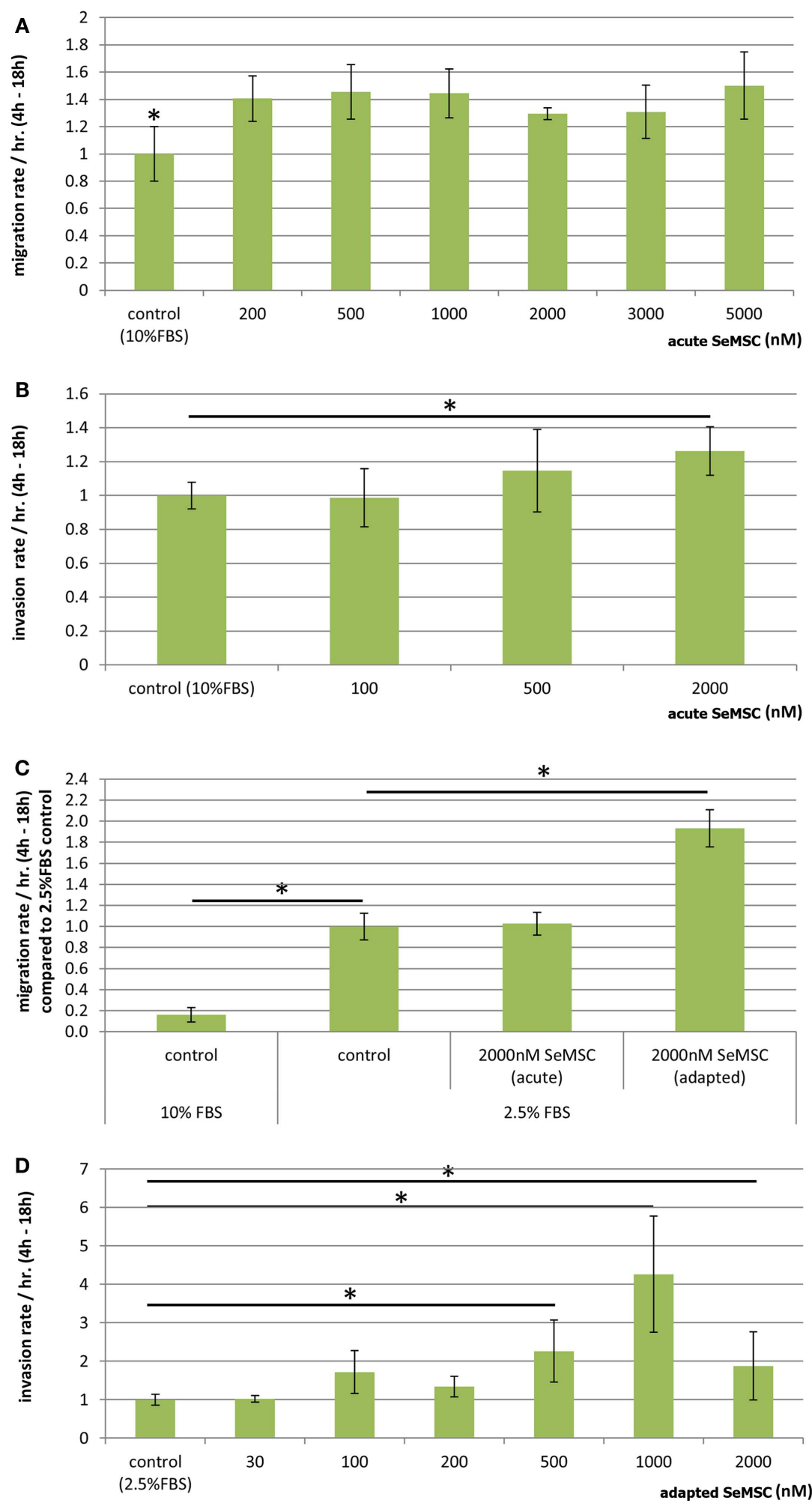

FIGURE 4 | Migration and invasion of PC3 cells after selenium treatment. Dose-response study of acute SeMSC treatment on

(A) migration of PC3 cells cultured in 10\% serum containing media

(B) invasion of PC3 cells cultured in 10\% serum containing media,

(C) migration of 10 and $2.5 \%$ serum cultured cells with acute or long term adapted SeMSC treatment, (D) $44 \mathrm{~h}$ dose-response study of long term/adapted SeMSC treatment on invasion of $2.5 \%$ serum cultured cells. Bar charts represent average migration or invasion rate per hour during the linear range of the $24 \mathrm{~h}$ assay, three biological replicates, error bars \pm SD. ${ }^{*} p<0.01$. 
invasion is a reflection of increased migration or a combination of increased migration and remodeling of the extracellular matrix. It is hereby important to determine the matrix stiffness as it has been shown that tumor cells can invade extracellular matrices in a protease-independent manner at relatively low matrix stiffness (37). Future work is also needed to investigate which selenium dependent/responsive proteins are involved in this process.

The results of this work indicate that it is essential to determine the selenium sensitivity of an in vitro model before investigating the effects of selenium compounds on biological processes, or before comparing models. It also underlines that "golden standard" dose-response curves may not be the best method to determine "physiologically relevant" in vitro micronutrient concentrations. It might be more advisable to use appropriate biomarker assessment in future in vitro studies.

\section{ACKNOWLEDGMENTS}

We gratefully acknowledge the support from the European Union Framework Programme 7 SaveMe project to Julie Decock and from a Norwich Research Park studentship to Wouter Hendrickx.

\section{REFERENCES}

1. Fairweather-Tait SJ, Bao Y, Broadley MR, Collings R, Ford D, Hesketh JE, et al. Selenium in human health and disease. Antioxid Redox Signal (2011) 14(7):1337-83. doi:10.1089/ ars. 2010.3275

2. Papp LV, Lu J, Holmgren A, Khanna KK. From selenium to selenoproteins: synthesis, identity, and their role in human health. Antioxid Redox Signal (2007) 9(7):775-806. doi:10.1089/ars.2007.1528

3. Hurst R, Hooper L, Norat T, Lau R, Aune D, Greenwood DC, et al. Selenium and prostate cancer: systematic review and meta-analysis. Am J Clin Nutr (2012) 96(1):111-22. doi:10.3945/ajen.111.033373

4. Sabichi AL, Lee JJ, Taylor RJ, Thompson IM, Miles BJ, Tangen $\mathrm{CM}$, et al. Selenium accumulation in prostate tissue during a randomized, controlled short-term trial of L-selenomethionine: a Southwest Oncology Group study. Clin Cancer Res (2006) 12(7 Pt 1):2178-84. doi: 10.1158/1078-0432.CCR-05-0937

5. Takata Y, Morris JS, King IB, Kristal AR, Lin DW, Peters U. Correlation between selenium concentrations and glutathione peroxidase activity in serum and human prostate tissue. Prostate (2009) 69(15):1635-42. doi:10.1002/pros.21012

6. Tsavachidou D, McDonnell TJ, Wen S, Wang X, Vakar-Lopez F, Pisters LL, et al. Selenium and vitamin E: cell type- and intervention-specific tissue effects in prostate cancer. J Natl Cancer Inst (2009) 101(5):306-20. doi:10.1093/jnci/djn512

7. Yu MW, Horng IS, Hsu KH, Chiang YC, Liaw YF, Chen CJ. Plasma selenium levels and risk of hepatocellular carcinoma among men with chronic hepatitis virus infection. Am J Epidemiol (1999) 150(4):367-74. doi:10.1093/ oxfordjournals.aje.a010016

8. Cai W, Deng JY, Ouyang B, Li P, Li F, Zhou DY, et al. Surveillance on Keshan disease from
1990 to 2008 in Sichuan province. Zhonghua Liu Xing Bing Xue Za Zhi (2009) 30(8):820-3.

9. Sunde RA, Raines AM, Barnes KM, Evenson JK. Selenium status highly regulates selenoprotein mRNA levels for only a subset of the selenoproteins in the selenoproteome. Biosci Rep (2009) 29(5):329-38. doi: 10.1042/BSR20080146

10. Cheng W, Fu YX, Porres JM, Ross DA, Lei XG. Selenium-dependent cellular glutathione peroxidase protects mice against a pro-oxidantinduced oxidation of NADPH, NADH, lipids, and protein. FASEB $J$ (1999) 13(11):1467-75.

11. Lu J, Holmgren A. Selenoproteins. J Biol Chem (2009) 284(2):723-7. doi:10.1074/jbc.R800045200

12. Karunasinghe N, Ferguson LR, Tuckey J, Masters J. Hemolysate thioredoxin reductase and glutathione peroxidase activities correlate with serum selenium in a group of New Zealand men at high prostate cancer risk. J Nutr (2006) 136(8):2232-5.

13. Yoon SO, Kim MM, Chung AS. Inhibitory effect of selenite on invasion of HT1080 tumor cells. J Biol Chem (2001) 276(23):20085-92. doi:10.1074/jbc.M101143200

14. Zeng H, Briske-Anderson M, Idso JP, Hunt CD. The selenium metabolite methylselenol inhibits the migration and invasion potential of HT1080 tumor cells. J Nutr (2006) 136(6):1528-32.

15. Yan L, Frenkel GD. Inhibition of cell attachment by selenite. Cancer Res (1992) 52(20):5803-7.

16. Rooprai HK, Kyriazis I, Nuttall RK, Edwards DR, Zicha D, Aubyn D, et al. Inhibition of invasion and induction of apoptosis by selenium in human malignant brain tumour cells in vitro. Int J Oncol (2007) 30(5):1263-71.

17. Song H, Kim J, Lee HK, Park HJ, Nam J, Park GB, et al. Selenium inhibits migration of murine melanoma cells via down-modulation of IL-18 expression. Int Immunopharmacol (2011) 11(12):2208-13. doi:10.1016/j.intimp.2011.10.002

18. Xiang N, Zhao R, Zhong W. Sodium selenite induces apoptosis by generation of superoxide via the mitochondrial-dependent pathway in human prostate cancer cells. Cancer Chemother Pharmacol (2009) 63(2):351-62. doi:10.1007/s00280008-0745-3

19. Kandas NÖ, Randolph C, Bosland MC. Differential effects of selenium on benign and malignant prostate epithelial cells: stimulation of LNCaP cell growth by noncytotoxic, low selenite concentrations. Nutr Cancer (2009) 61(2):251. doi:10.1080/ 01635580802398430

20. Menter DG, Sabichi AL, Lippman SM. Selenium effects on prostate cell growth. Cancer Epidemiol Biomarkers Prev (2000) 9(11):1171-1182.

21. Sinha R, Pinto JT, Facompre N, Kilheffer J, Baatz JE, ElBayoumy K. Effects of naturally occurring and synthetic organoselenium compounds on protein profiling in androgen responsive and androgen independent human prostate cancer cells. Nutr Cancer (2008) 60(2):267-75. doi:10.1080/ 01635580701630479

22. Ip C, Thompson HJ, Zhu Z Ganther HE. In vitro and in vivo studies of methylseleninic acid: evidence that a monomethylated selenium metabolite is critical for cancer chemoprevention. Cancer Res (2000) 60(11):2882-6.

23. Pinto JT, Sinha R, Papp K, Facompre ND, Desai D, El-Bayoumy K. Differential effects of naturally occurring and synthetic organoselenium compounds on biomarkers in androgen responsive and androgen independent human prostate carcinoma cells. Int $J$ Cancer (2007) 120(7):1410-7. doi:10.1002/ ijc. 22500
24. Yang X, Tian Y, Ha P, Gu L. Determination of the selenomethionine content in grain and human blood. Wei Sheng Yan Jiu (1997) 26(2):113-6.

25. Cai XJ, Block E, Uden PC, Zhang X, Quimby BD, Sullivan JJ. Allium chemistry: identification of selenoamino acids in ordinary and selenium-enriched garlic, onion, and broccoli using gas chromatography with atomic emission detection. J Agric Food Chem (1995) 43(7):1754-7. doi:10.1021/ jf00055a001

26. Schrauzer GN. Nutritional selenium supplements: product types, quality, and safety. $J \mathrm{Am}$ Coll Nutr (2001) 20(1):1-4. doi:10.1080/ 07315724.2001 .10719007

27. Nève J. Human selenium supplementation as assessed by changes in blood selenium concentration and glutathione peroxidase activity. J Trace Elem Med Biol (1995) 9(2):65-73. doi:10.1016/S0946672X(11)80013-1

28. Rebsch CM, Penna FJ, Copeland PR. Selenoprotein expression is regulated at multiple levels in prostate cells. Cell Res (2006) 16(12):940-8. doi:10.1038/sj.cr.7310117

29. Jerome-Morais A, Wright ME, Liu R, Yang W, Jackson MI, Combs $\mathrm{GF} \mathrm{Jr}$, et al. Inverse association between glutathione peroxidase activity and both seleniumbinding protein 1 levels and Gleason score in human prostate tissue. Prostate (2011) 72(9):1006-12. doi:10.1002/pros.21506

30. Lincoln DT, Ali Emadi EM, Tonissen KF, Clarke FM. The thioredoxinthioredoxin reductase system: overexpression in human cancer. Anticancer Res (2003) 23(3B):2425-33.

31. Shi C, Yu L, Yang F, Yan J, Zeng H. A novel organoselenium compound induces cell cycle arrest and apoptosis in prostate cancer cell lines. Biochem Biophys Res Commun (2003) 309(3):578-83. doi:10.1016/ j.bbrc.2003.08.032 
32. Karlenius TC, Shah F, Yu WC, Hawkes HJ, Tinggi U, Clarke FM, et al. The selenium content of cell culture serum influences redoxregulated gene expression. Biotechniques (2011) 50(5):295-301.

33. Jung K, Seidel B, Rudolph B, Lein M, Cronauer MV, Henke W, et al. Antioxidant enzymes in malignant prostate cell lines and in primary cultured prostatic cells. Free Radic Biol Med (1997) 23(1):127-33. doi: 10.1016/S0891-5849(96)00613-2

34. Barrera LN, Cassidy A, Johnson IT, Bao Y, Belshaw NJ. Epigenetic and antioxidant effects of dietary isothiocyanates and selenium: potential implications for cancer chemoprevention. Proc Nutr
Soc (2012) 71(2):237-45. doi:10. 1017/S002966511200016X

35. Lim HW, Hong S, Jin W, Lim S, Kim SJ, Kang HJ, et al. Up-regulation of defense enzymes is responsible for low reactive oxygen species in malignant prostate cancer cells. Exp Mol Med (2005) 37(5):497-506. doi:10. 1038/emm.2005.62

36. Carlson BA, Yoo MH, Sano Y, Sengupta A, Kim JY, Irons R, et al. Selenoproteins regulate macrophage invasiveness and extracellular matrix-related gene expression. BMC Immunol (2009) 10:57. doi:10.1186/1471-2172-10-57

37. Ehrbar M, Sala A, Lienemann P, Ranga A, Mosiewicz K, Bittermann $A$, et al. Elucidating the role of matrix stiffness in 3D cell migration and remodeling. Biophys (2011) 100(2):284-93. doi:10.1016/ j.bpj.2010.11.082

Conflict of Interest Statement: The authors declare that the research was conducted in the absence of any commercial or financial relationships that could be construed as a potential conflict of interest.

Received: 03 June 2013; accepted: 29 August 2013; published online: 23 September 2013.

Citation: Hendrickx W, Decock J, Mulholland F, Bao $Y$ and FairweatherTait S (2013) Selenium biomarkers in prostate cancer cell lines and influence of selenium on invasive potential of PC3 cells. Front. Oncol. 3:239. doi: 10.3389/fonc.2013.00239

This article was submitted to Molecular and Cellular Oncology, a section of the journal Frontiers in Oncology.

Copyright (C) 2013 Hendrickx, Decock, Mulholland, Bao and Fairweather-Tait. This is an open-access article distributed under the terms of the Creative Commons Attribution License (CC BY). The use, distribution or reproduction in other forums is permitted, provided the original author(s) or licensor are credited and that the original publication in this journal is cited, in accordance with accepted academic practice. No use, distribution or reproduction is permitted which does not comply with these terms. 